\title{
THE LOCATIONAL CRITERIA OF FOOTLOOSE FIRMS: A FORMAL MODEL
}

\author{
Ralph C. Allen and Jack H. Stone*
}

\section{Introduction}

A "footloose" industry was defined originally by William Alonso (1972, p. 33) and Edgar Hoover (1948, p. $36 \mathrm{n})$, as an industry for which transport costs are relatively unimportant. Thus the location decisions of these industries are free of the constraint of assembly and distribution costs.

Alonso $(1972$, p. 33), identified three mechanisms that can make an industry more footloose. The first is a decline in the relative prices of transported inputs. The second is a decline in the weight of transported materials per unit of output. The third is an improvement in or more complex processing of products, making the value of transported inputs smaller relative to the value of the final product.

Alonso (1972, p. 33) further states that the removal of transport constraints does not mean that a footloose industry chooses its locations randomly. ${ }^{1}$ James Heilbrun (1981, p. 80), referring to the use of the term footloose by Alonso, reinforces the point that "footloose" does not mean randomness in choice of locations but asserts that such industries "... use some other (non-transport) criterion in choosing a location." While Heilbrun suggests that footloose industries are production cost (rather than transport cost) oriented, this early literature did not define the conditions under which production cost becomes the only location criterion nor specify what the non-transport, production cost factors are. ${ }^{2}$

The purpose of this paper is to develop a formal model of a footloose firm, and to use this model to analyze the conditions that establish transport footlooseness and the location orientation of the firm. Using this model, the paper also will investigate the mechanisms that Alonso and others suggested would create footlooseness.

\section{Model of a Footloose Firm in a Weberian Framework}

Most definitions of a footloose firm assume a multiinput firm that must choose a location from among a set of sites that includes as two possibilities the market site and

*Associate Professors of Economics, Valdosta State College and Spelman College. the source of a transportable input. The assumption here is a single-establishment firm that employs two inputs, $R$ and $\mathrm{J}$, and supplies a single final product, $\mathrm{Q}$, to a single market center. The input $R$ is transported from its source, site $z$, to the firm, and the final product is transported from the firm to the market site, $c{ }^{3}$. The firm may be located at any point (denoted by $\mathrm{f}$ ) on the surface that includes sites $\mathrm{z}$ and $\mathrm{c}$. Figure 1 illustrates the locations of the market and of the source of input $R$ and the potential locations of the firm.

Assuming that the firm is a price taker in the product and resource markets, the firm will attempt to choose a resource mix and location that will maximize profits, $P$, given by:

$$
P=q Q-r R-j J
$$

The product price, $q$, and the prices, $r$ and $j$, of the resources, $R$ and J, respectively, are evaluated at the firm site.

Since the final product is transported, the product price is the price, $q_{0}$, at the market site less transport costs, T, i.e.,

$$
q=q_{0}-T
$$

The cost per unit of resource $R$ at the firm site is the price, $r_{0}$, at the input source plus shipping costs, $S$, i.e.,

In general,

$$
r=r_{0}+S \text {. }
$$

$$
\begin{aligned}
& T=T\left(X_{f}, Y_{f} ; X_{c}, Y_{f}\right) \\
& S=S\left(X_{f}, Y_{f} ; X_{z}, Y_{z}\right),
\end{aligned}
$$

where the $X_{i}$ and $Y_{i}$ are the location coordinates from Figure 1. For the Weber model the transport costs, $T$ and $S$, are determined by distance only, and not by specific location. Thus for $\mathrm{h}$, the distance between the market and the firm, and $k$, the distance between the source of $R$ and the firm, we have:

and

$$
\begin{aligned}
& h=\left[\left(X_{f}-X_{c}\right)^{2}+\left(Y_{f}-Y_{f}\right)^{2}\right]^{1 / 2} \\
& k=\left[\left(X_{f}-X_{z}\right)^{2}+\left(Y_{f}-Y_{z}\right)^{2}\right]^{1 / 2}
\end{aligned}
$$

$$
\begin{aligned}
& T=T(h) \\
& S=S(k),
\end{aligned}
$$

where $\mathrm{k}+\mathrm{h}=\mathrm{L}$ the total shipping distance.

Input J is the bundle of "other criteria" that controls the location of a firm that is free of transport constraints. These other criteria have been identified variously in the literature on footloose firms and several examples of these criteria are presented in Table 1. One characteristic common to all the other criteria is that they involve resources that are not the traditional natural resources discussed in 


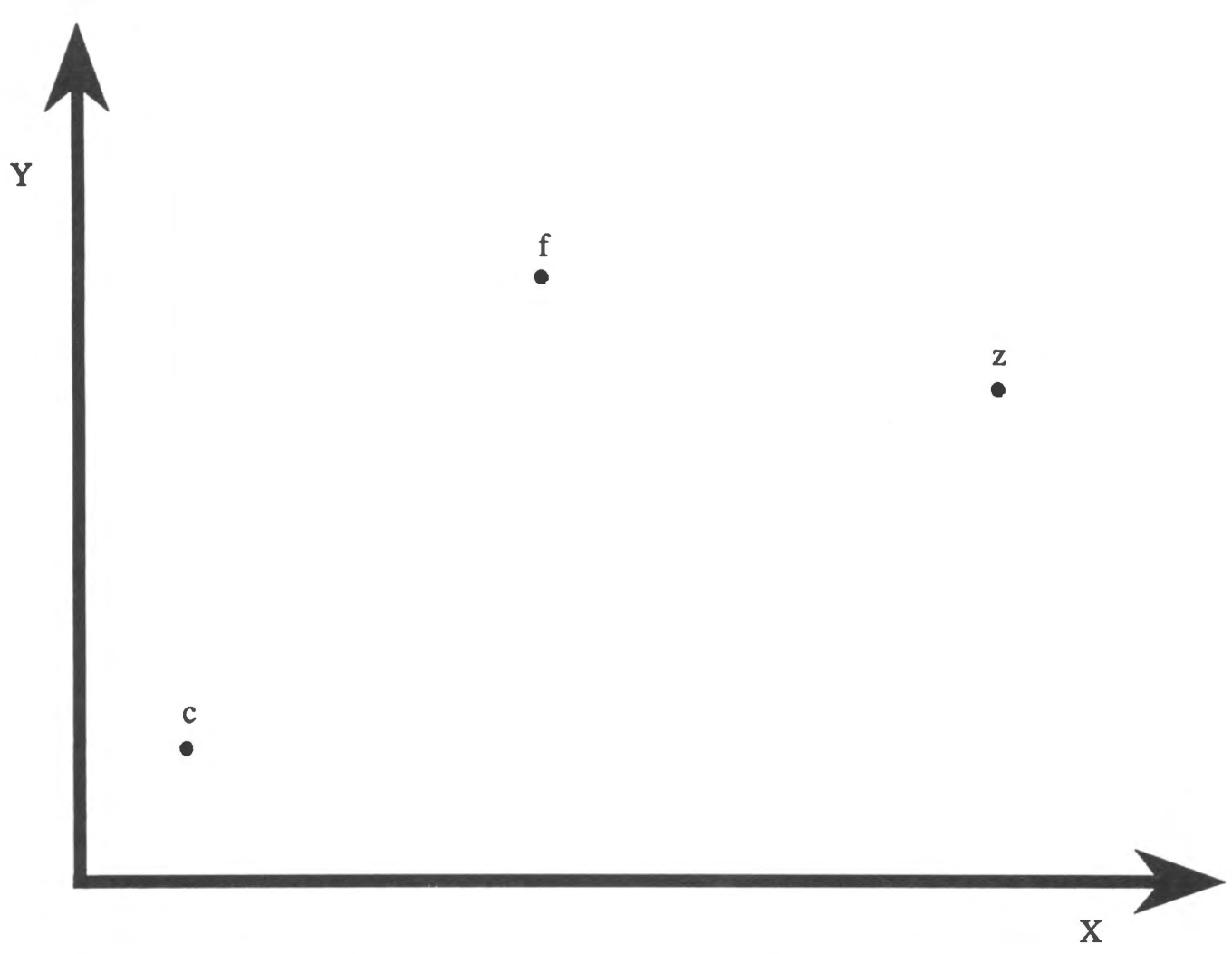

Figure 1. Sites of the Firm (f), Resource (z) and Market (c).

the literature growing out of the Weber model.

Heilbrun (1981,p. 80) warns, however, that many of these suggested orientations are in reality the result of transport outlays. For example, nearness to a communications center reduces cost to the firm primarily by reducing the cost of transporting managers and information. Growth in market size allows firms to specialize and take advantage of agglomeration economies, but it is the cost of transporting the specialized intermediate goods and services that encourages the firms to cluster and form urban areas. The existence of amenities at certain sites encourages labor to congregate and to bid wages down at those sites. The firm could, however, pay higher wages away from the amenity sites to compensate workers for travel and other costs of moving to and from the sites with the desired amenities. In a spatial context, variations in price and thus in costs to firms exist as a result of transport costs.

Given that these other criteria are no less transport based than the traditional natural resource in the Weber model, it is tempting to regard the footloose firm as one whose location is as constrained by transport-oriented factors as the transport-oriented firm in the Weber model, with the only (and possibly trivial) difference being that in the footloose case the constraining resource is not a tradi- tional Weberian natural resource. Another interpretation is possible, however. This involves the assumption that supplies of J are spatially ubiquitous and characterized by a spatial variation in the FOB price of $J$ that must satisfy the constraint that, for all $i$, the difference in the FOB price per unit of distance from the ith site always is less than the transport rate associated with the input J. This assumption ensures that a firm locating at any site always will find it less costly to use J located at that site than to transport it from another site.

Thus in contrast to the assumption concerning the transport oriented firm in the traditional Weber model, $\mathrm{J}$ is a nontransported ubiquitously available input whose price is a function of location only and not dependent on the distance from another site. Under this interpretation, $\mathrm{J}$ is not only different in nature from the traditional Weberian natural resource input but functionally and behaviorally different. For example, referring to Table 1, if the location of the footloose firm has an "adequate supply" or a "good, flexible pool of labor" (which can be interpreted to mean labor of a given skill can be obtained at an attractively low price), for labor to qualify as a $\mathrm{J}$ input, the firm must find the difference in FOB wage rates per unit distance between any two sites less than the "transportation rate" of labor (the 
wage differential per unit distance required to attract commuting workers from the other location). Thus labor supplies located at any site always will be used rather than supplies transported from an alternative site. Likewise, consider environmental services as a potentially transportable input. While not an explicitly priced resource that enters the production process directly as does a Weberian natural resource, environmental services are generated at different levels at various sites thereby creating differentials in the supply prices of other directly utilized inputs offered at different sites. If "[m]anagement would like the factory to be located in a place which is pleasant environmentally", for environmental services to qualify as a $\mathrm{J}$ resource, the cost of "transporting" environmental services between two sites must always exceed the per unit FOB supply price differential of these other directly utilized inputs offered at the respective sites. This ensures that environmental services always are used at the site chosen for the location of the firm rather than "transported" from another site.

Given that the price of J has locational factors but not those (by the traditional definition) that are related to the transport of $\mathrm{J}$, the price of input $\mathrm{J}$ at the firm is expressed as:

$$
j=j\left(X_{f}, Y_{f}\right) \text {. }
$$

Price, $\mathrm{j}$, has locational orientation, but this orientation is independent of distance and thus transport.

Assuming constant returns to scale in production and fixed resource proportions, the objective of the firm is to find the particular location that minimizes the transport and production costs of producing a particular level of output Q*. Given

and total costs

$$
Q^{*}=\min [a R, b J]
$$

$$
\mathrm{TC}=\mathrm{Q}^{*}\left[\mathrm{~T}+\left(\mathrm{r}_{0}+\mathrm{S}\right) / \mathrm{a}+\mathrm{j} / \mathrm{b}\right]
$$

under what conditions is the firm free of distribution, $\mathrm{T}$, and assembly, $\mathrm{S}$, and thus free to base its location decision on the locational price of input $\mathrm{J}$ ?

\section{The Footloose Firm}

For complete freedom $(\mathrm{T}+\mathrm{S} / \mathrm{a})$ must be a constant for all $h$ and $L(k=L-h)$, i.e.,

$$
\mathrm{dT} / \mathrm{dh}-(\mathrm{dS} / \mathrm{dk}) / \mathrm{a}=0 \text {, }
$$

and

$$
(\mathrm{dS} / \mathrm{dk}) / \mathrm{a}=0,
$$

for all $\mathrm{L}$ and $\mathrm{h}$. Thus $\mathrm{T}$ and $\mathrm{S}$ must be constants. ${ }^{5}$ This situation may be referred to as the "first class stamp" case in which transport cost is a function only of number of units shipped and not distance. In this case, footlooseness is independent of the importance of transport costs in total cost and of the mechanisms described by Alonso.

A less restrictive form of freedom specifies that the firm is free of transport constraints to the extent that these costs would not prevent the firm from locating at the most favorable location for obtaining the input $J$. Assume that $\left(X_{f}^{\prime}, Y_{f}^{\prime}\right)$ is the coordinate where $j\left(X_{f}, Y_{f}\right)>j\left(X_{f}^{\prime}, Y_{f}^{\prime}\right)$ for all $\left(X_{\mathrm{F}} Y_{\mathrm{f}}\right)$. For $\left(\mathrm{X}_{\mathrm{f}}^{\prime}, \mathrm{Y}_{\mathrm{f}}^{\prime}\right)$ to be the choice site:

$$
\begin{aligned}
& \mathrm{Q}^{*}\left[\mathrm{~T}(\mathrm{~h})+\left(\mathrm{r}_{0}+\mathrm{S}(\mathrm{k})\right) / \mathrm{a}+\mathrm{j}\left(\mathrm{X}_{\mathrm{f}}, \mathrm{Y}_{\mathrm{f}}\right) / \mathrm{b}\right]> \\
& \mathrm{Q}^{*}\left[\mathrm{~T}\left(\mathrm{~h}^{\prime}\right)+\left(\mathrm{r}_{0}+\mathrm{S}\left(\mathrm{k}^{\prime}\right) / \mathrm{a}+\mathrm{j}\left(\mathrm{X}_{\mathrm{f}}^{\prime}, Y_{\mathrm{f}}^{\prime}\right) / \mathrm{b}\right]\right.
\end{aligned}
$$

for all $\left(\mathrm{X}_{\mathrm{f}} \mathrm{Y}_{\mathrm{f}}\right)$. Rewriting equations (15), we have the condition that ensures footlooseness:

$$
\begin{gathered}
{\left[j\left(X_{f}, Y_{f}\right)-j\left(X_{f}^{\prime}, Y_{f}^{\prime}\right)\right] / b>\left[T\left(h^{\prime}\right)-T(h)\right]+} \\
{\left[S\left(k^{\prime}\right)-S(k)\right] / a .}
\end{gathered}
$$

What impacts do the mechanisms identified by Alonso have on the state of the inequality in equation $16 ?^{6}$ As Alonso predicted, a proportional decrease in all transport rates will increase the footlooseness of a firm. A reduction in the transport rate for either the final product or the transported resource $R$, however, may increase or decrease the footlooseness depending on whether [ $T\left(h^{\prime}\right)$ $\mathrm{T}(\mathrm{h})]$ or $\left[\mathbf{S}\left(\mathbf{k}^{\prime}\right)-\mathbf{S}(\mathbf{k})\right]$ is positive or negative, respectively. Thus, in this framework, changes in transport rates are far less unambiguous than suggested by Alonso.

Given the transport rates and price gradient for input $\mathrm{J}$, a technological change that decreases the use of input $\mathrm{J}$ (increases b) will decrease the footlooseness of the firm. This result is consistent with Alonso. A technological change that decreases the use of resource $R$ (increases a), however, may decrease or increase footlooseness depending on whether $S(k)$ is greater or less than $S\left(k^{\prime}\right)$.

These results become intuitive if one considers a case in which the firm transports resource R "past" the lowest cost $\mathrm{J}$ site to reach the firm. Any change that pulls the firm toward the resource site also pulls the firm toward the lowest cost J site. If, however, the lowest cost J site is beyond the firm site toward the market, then any change that pulls the firm toward the resource site pulls the firm away from the lowest cost J site.

\section{Conclusion}

A formal model of the footloose firm based on a Weberian framework has been developed in this paper. The model interprets the footloose firm as a firm that, although it may use traditional Weberian transported resources and may transport products to final markets, utilizes a ubiquitous but nonuniformly priced, nontransported resource that can determine location under certain conditions. The location criteria of such a firm and their relationship to the traditional footloose creating mechanisms of Alonso were developed. The formal modeling of the footloose firm supports some of the conclusions of Alonso but expands his analysis by demonstrating that transport rate and technological change produce richer results than were suggested by Alonso. 
Table 1

Sample of Quotations Illustrating Locational

Orientations of Footloose Firms

\begin{tabular}{|c|c|c|}
\hline Author & Quotation & Orientation \\
\hline Bale (1977, p. 131) & "An adequate supply must be available." & Labor \\
\hline Bale $(1977$, p. 133) & $\begin{array}{l}\text { "Location near an airport. . . would be helpful since } \\
\text { [the firm] will need quick and frequent contact with } \\
\text { headquarters" }\end{array}$ & Communication \\
\hline Spiegleman (1964, p. 86) & $\begin{array}{l}\text { "... the manner in which the [precision instruments] } \\
\text { industry grows enhances the tendency to cluster..." }\end{array}$ & Urbanization \\
\hline Bale $(1977$, p. 133$)$ & $\begin{array}{l}\text { "Management would like the factory to be located in a } \\
\text { place which is pleasant environmentally" }\end{array}$ & Amenity \\
\hline Schmenner $(1982$, p. 38) & $\begin{array}{l}\text { "Since proximity to markets or supplies is not } \\
\text { essential. .., such firms can be extraordinarily } \\
\text { free to locate in attractive places ... to live" }\end{array}$ & Amenity \\
\hline Torres $(1977$, p. 30$)$ & $\begin{array}{l}\text { Footloose firms are attracted to" ... medium-sized } \\
\text { metropolitan area(s) with plenty of recreational } \\
\text { activities, a good, flexible pool of labor ... quality } \\
\text { of life" }\end{array}$ & Amenity; Labor \\
\hline Kahley (1986, p. 18) & $\begin{array}{l}\text { "Amenities such as climate and recreational activities } \\
\text { thus can be important factors in location decisions..." }\end{array}$ & Amenity \\
\hline $\begin{array}{l}\text { Mills and Hamilton } \\
(1984, \text { p. 30) }\end{array}$ & $\begin{array}{l}\text { "... This state of being footloose has led to an } \\
\text { amenity orientation,... . pleasant locational attributes- } \\
\text { say, climate or culture-rather than upon transport or } \\
\text { production cost." }\end{array}$ & Amenity \\
\hline
\end{tabular}

Notes

${ }^{1}$ Not all authors agree with this characterization of footlooseness. David Pearce states that footloose firms "can effectively locate anywhere (1986, p. 158)."

${ }^{2}$ Again, the footloose concept is not used consistently. Beckman states, "[W]hen a significant part of the inputs or outputs is transported, the activity is often called footloose. The choice of location is said to be transport oriented (1968, p. 10)." Mills and Hamilton $(1984$, p. 30 ) state that for the footloose firm, both transport costs and interregional input price difference have declined so that neither transport nor production cost is location constraining.

${ }^{3}$ A number of authors, e.g., Bale (1977) and Ruane (1987), have suggested that the key to footlooseness is ubiquitous, uniformly-priced resource and product markets. For this case transport costs do not exist and thus are irrelevant to location choice.

${ }^{4}$ See for example the discussion by Nourse (1968, p. 53).
If all possible firm locations are on the line between the resource site and the market site, then $\mathrm{L}=\mathrm{h}+\mathrm{k}$ becomes a constant and a less restrictive transport cost relationship can be stated. For the line case, $T(h)=v h$ and $S(k)=a v k$, for $v, a$ constant, is sufficient for footlooseness. This case is referred to by many authors, e.g., Yarbrought and Yarbrought(1988, p. 142), as the case when manufacturing is weight preserving and the transport rate is determined by weight.

'In contrast to the statement of Alonso, the market prices of the final product and resource $R$ have no effect on the footloose condition in equation 16 . This result is partially the consequence of the Weberian framework.

\section{References}

Alonso, William, "Location Theory," Regional Development and Planning: A Reader, by John Friedmann and William Alonso, Editors, MIT Press, Cambridge, MA, 1964, reprinted in Readings in Urban Economics, by Matthew Edel 
and Jerome Rothenberg, Macmillan, New York, NY, 1972, 16-37.

Bale, John, The Location of Manufacturing Industry: An Introductory Approach, Oliver and Boyd, 1977.

Beckman, Martin, Location Theory, Random House, New York, 1968.

Heilbrun, James, Urban Economics and Public Policy, St. Martins, New York, 1981.

Hoover, Edgar M. The Location of Economic Activity, McGrawHill Book Company, Inc., New York, 1948.

Kahley, William J., "What's Behind Patterns of State Job Growth," Economic Review, Federal Reserve Bank of Atlanta, May, 1986, 4-26.

Mills, Edwin S. and Bruce W. Hamilton, Urban Economics, Scott Foreman and Company, Glenview, Illinois, Third Edition, 1984.

Nourse, Hugh O., Regional Economics, McGraw-Hill, New
York, 1968.

Pearce, David W., Editor, The MIT Dictionary of Modern Economics. The MIT Press, Cambridge, MA, Third Edition, 1986.

Ruane, Frances P., "Spatial Bias and the Location of Footloose Industry: A Simple Regional Model," Canadian Joumal of Economics, Vol. 20 \#3, August 1987, 506-517.

Schmenner, Roger W., Making Business Location Decisions, Prentice Hall, 1982.

Spiegleman, Robert G., "A Method for Analyzing the Location Characteristics of Footloose Industries: A Case Study of the Precision Instruments Industry," Land Economics, Vol. 40, Feb. 1964, 79-86.

Torres, Juan de, “'Footloose' But Not All Fancy-Free," Across the Board, June 1977, 27-33.

Yarbrought, Beth V. and Robert M. Yarbrought, The World Economy, The Dryden Press, New York, 1988. 